\title{
MANUFACTURING SIMULATION CONSULTANT'S FORUM
}

\author{
Chair \\ F. Bradley Armstrong \\ ABB Power T\&D Company Inc. \\ Electric systems Technology Institute \\ 1021 Main Campus Drive \\ Raleigh, NC 27606-5202, U.S.A. \\ Michelle Benjamin \\ Textile/Clothing Technology Corporation \\ 211 Gregson Drive \\ Cary, NC 27511, U.S.A. \\ Rich Kilgore \\ Thread Technologies \\ P. O. Box 7 \\ Chesterfield, MO 63017, U.S.A. \\ Panelists

Marvin Seppanen
Productive Systems
Route 5, Box 46
Winona, MN 55987, U.S.A.
Charles White
DuPont
1007 Market Street
Wilmington, DE 19898, U.S.A.

\begin{abstract}
Consultants are an important segment of the manufacturing simulation community because they are on the forefront of change and innovation. From their position they have much to offer the rest of the community. This session offers the panelists and audience the opportunity to share their thoughts and views on the factors influencing the success or failure of simulation projects.
\end{abstract}

\section{INTRODUCTION}

This year's panel is organized around the theme: Performing Successful Manufacturing Simulation Projects. The intent is to share experiences and opinions related to factors that most influence the outcome of simulation projects done in manufacturing environments.

Each panelist was asked to tackle the issue of critical success or failure factors for manufacturing simulation projects. Behind this task lay a fundamental question; namely, how does one define success? I found it interesting that not one panelist asked for clarification about what constituted project success. I suggest that everyone who has tackled a simulation project has experienced both "the thrill of victory and the agony of defeat". I believe it is the sum of these experiences that define success and failure for an individual. But because it is experience based, it is rare to hear people discuss this topic.

I find the definition of simulation project success very provocative because I think it is at the root of much of the conflict that occurs between consultants, vendors and clients. The definition of simulation success also has repercussions for specific issues such as formal simulation certification (as has been proposed), and generally being able to differentiate between simulation products and service providers. Fortunately, this panel is exploratory by nature, and is intended to get people thinking and not simply to serve up pat answers. Having said this, however, I offer a simple simulation project success definition: a working simulation model and a happy client. The two key words in this definition are "working" and "happy" and, unfortunately, there are many ways to achieve this success - few good and many bad. It is important to note that, by definition, a client will not be able to tell the difference. Based on my experience, project success is a continuum, but there are at least three key levels.

\section{Stage 1: The Model}

The analyst focuses on system details and presentation "spin" often resulting in a short-term, "feel-good" result 
that can create a backlash against simulation because no action or wrong actions were taken as a result of the project.

Unfortunately, many analysts are "one-shot wonders" who do one or two simulation projects and then jump to something else to avoid any backlash from a weak result. This backlash does not go away, but is vented against simulation as an analysis tool and the simulation product instead of the analyst who executed poorly. This type of "success" is the bane of the simulation community.

\section{Stage 2: The Problem}

The question at stage 2 shifts from "can I" to "how should I" model. It is a change from a model perspective to a project perspective. Most simulation training starts with the premise of a well-defined problem. Unfortunately, well-defined problems are rarely presented to a consultant, and if one is, it is probably not the real problem. The experienced analyst works on defining the problem properly for simulation and then explaining the problem and process to the client. Properly executed, this approach brings quantifiable benefits through implemented actions based on project results.

There is still room at this level for abuse if the consultant can convince the client to pay more and wait longer than necessary.

\section{Stage 3: The Process}

Only after a consultant has a firm grasp of modeling and effective problem solving skills can he or she take advantage of the simulation literature that focuses on the best ways of completing various aspects of simulation and analysis. It is at this level that consultants often start focusing on solving not just a single problem, but a class of problems through generic modeling and analysis.

\section{THE PANEL}

The panelists, as evidenced by their biographies, are a diverse group of experienced manufacturing simulation consultants. Each of the panelists has selected a question or statement related to the general theme and will moderate a discussion using their topic as a departure point. The remainder of this section lists the topics and a brief position or background statement.

\subsection{Brad Armstrong: The Ten Signs Your Project Is Headed for Trouble (and what you can do)}

Having been involved in dozens of simulation projects over the years (either doing them myself, or overseeing and advising others), I have had many opportunities to look back over a project and pinpoint where it ran into trouble (sometimes fixable, but other times not). As this forum is intended to share knowledge gained through experience and not a textbook, I thought I would share a list of ten statements you never want to hear and why.

\section{1. "I can't tell you what I want, but I'll know it when} I see it."

Make clients commit by telling them they can change their minds later (but only after you decide whether the change requires a scope and cost change). Even experienced consultants can get burned here if they have done similar kinds of projects previously. The consultant will gamble that he can steer the client to the "right" objectives instead of risking a confrontation at the outset of the project.

2. 'Don't worry, we have all the data you'll need." Clients often say this when negotiating price - don't believe it. Always worry about data. Not only whether it exists, but whether it is accurate, in the correct form, and can be manipulated easily (on computer versus hard copy).

3. "Where did I get this number? I don't remember."

Document your data. Always list the source, date, and any analysis performed for any data used in a model. This helps you on the project as well as those who follow after you and want to use your work.

4. "I didn't know how to model it, so I just assumed it away."

I had an analyst tell me this when I was reviewing a model she had built. Often new modelers will get in over their heads on a project and believe the only real sin is not to have a working model - everything else can be fixed later. New modelers should always ask for help before taking shortcuts.

5. "I'm not worrying about what analysis I want to do until after I get my model working."

New users often lose sight of the fact that the entire purpose of the model is to allow an objective to be met by performing an analysis. Clients unfamiliar with simulation often exhibit the same attitude. This model building approach is doomed unless a "pretty picture" is the only objective.

6. "No matter how much better and faster I make my interface, the designers still can't change the data fast enough."

An analyst who had a computer science background was building a model for a new manufacturing line but could not do any analysis because the designers were keeping him too busy changing data. His solution was to build an interface so that they could 
input the data themselves. Of course, he never understood that the real problem was including too much detail in the model.

7. "Ms. Decision Maker, did you just say the key model assumption is wrong?"

It is a terrible feeling to find yourself in the final presentation and having a key assumption labeled wrong. Presumably you have spent all of the money and your credibility just died. Assumptions are the bridge between the model and your audience - use them wisely and make sure everyone understands and accepts them as soon as they are made.

8. "Well Mr. VP of Manufacturing, this confidence interval is based on 20 replications using antithetic pairs; it clearly shows that, assuming Normally distributed processing times and an alpha of 0.05 , the throughput goal is covered by the interval half-width."

A typical rookie mistake is to get so excited about the technical details that you want to share them with decision makers. Also, realize most managers have a much greater capacity for dealing with ambiguity than technical people. Most will use the information correctly, and a technically exact (but confusing) presentation will not help avoid information misuse.

9. "I was able to get the product cycle time from $10 \%$ of actual up to $80 \%$, but I think my 'adjustment' factors are too high."

This situation happened when an analyst I was supporting was given a model whose scope did not include the factors influencing the system performance measure. Therefore, his model did not match reality. His solution was to concoct "fudge" factors that were insupportable. $\mathrm{He}$ was bright enough to find a "remedy", but he lacked the experience to correctly identify the real problem.

10. "Well, yes, I suppose you could get the same answer using simple arithmetic."

Before building a simulation model, make sure you have not simplified it to the point where other, cheaper analysis methods can be used.

All of these situations have one thing in common. They could happen to you even if you know better. Maybe this reminder will keep you from getting caught up in the moment and do something you'll later regret; but if not, take comfort that others have suffered similar fates.

\subsection{Michelle Benjamin: Interviewing Skills}

In order to be a successful simulation consultant, a variety of skills are required. These skills include programming, statistical analysis, project management and interviewing. Simulation software vendors, universities and training programs offer courses in simulation programming and statistical analysis. These courses educate the developer on how to model various case studies and analyze the input and output data. However, such courses typically do not provide training on how to obtain the information required to define case studies. For example, how were the levels of detail, the performance measures, and the process steps determined?

A key factor to achieving a simulation project success is the interviewing skills of the consultant. Good interviewing skills will facilitate the process of obtaining goals and objectives, gaining an understanding of the system, defining appropriate assumptions and determining the project completion timeline. $\mathrm{Bad}$ interviewing skills cause the project to take longer to complete, cost more than expected, provide inaccurate results, include bad assumptions, and not solve the customer's problem.

As consultants, our goal is to solve our customer's problem(s). Clearly defining goals and objectives for a project will expedite the process of solving their problem(s). These goals and objectives will assist in determining the level of detail required, the scope, the performance measures, and the capability of the model.

A common purpose for using simulation is to understand the dynamics of a complex or non-existent system. For a complex system, the process is known, but typically not documented. If the consultant is an external consultant, limited knowledge of the system usually exists. Therefore, interviewing a system expert is required to define the process flow. However, the danger of interviewing the expert is that some tasks are performed subconsciously. Obtaining this subconscious information requires extensive questioning.

An approach to compensate for the lack of information is to build a model in multiple phases. First, obtain high level information and build a non-detailed model. Generally, the results will be less than desirable which tends to lead the customer to thinking of additional details. This will result in a cyclical process of determining additional information and adding the details to the model. Be cautious not to frustrate the expert of the system. The better the interviewing skills, the shorter the cyclical process will be.

Unfortunately, only practice will sharpen interviewing skills. Consultants who have the luxury of modeling similar systems (i.e. manufacturing processes, warehouses, distribution centers, etc.) will be able to obtain proper information faster than those who do not model similar systems. Manufacturing processes are similar in that finite capacity resources produce final product(s) out of raw material(s). Common information 
that needs to be obtained would be machine availability, machine capability, product routings, and product demand.

However, if given the opportunity to model similar systems, a consultant should not assume he/she is "familiar" with the system. If he/she assumes more knowledge about the system than he/she should, poor assumptions and an inaccurate representation of the system could be made.

Strong interviewing skills are critical to a consultant in determining the project's problem statement, goals and objectives, system description and level of detail. If this information is incorrect, the project will take longer than expected to complete, cost more than expected, and potentially, not solve the customer's problem.

\subsection{Rich Kilgore: "How Much Will the Simulation Project Cost and When Will We See the Results of This Model?"}

Simulation is a capital investment. The decision to make a capital investment is based on a comparison of the benefits of the investment (tangible and intangible) to the cost of the investment. While simulations are usually easy to justify based on potential benefits, an estimate of the cost of a simulation is a necessary task prior to project approval. And many projects will be tracked as successes or failures based on adherence to the cost and schedule, despite the quality of the outcome!

Estimating the cost of a simulation is closer to estimating the cost of oil exploration than estimating the cost of a building. Most buildings and construction techniques are similar enough that historical data can be used based on the project specifications (dollars per square foot). And during construction, it is easy to see the amount of work completed and the expected cost to complete the project. In oil exploration, you need to drill some test wells before you begin to learn the range of costs which will get you deep enough to expect results. Then you make the investment in the main well and then you continue to drill (and drill and drill) until something valuable emerges. Thus, it is not surprising that even for the most Experienced Simulation Consultants, the honest answer to the question of cost is "I really don't know!". Of course, if you want to become an Experienced Simulation Consultant, you must avoid the honest answer. The following alternatives are listed in order of preference:

\section{Estimate by analogy to similar projects based on a complete project specification.}

Work with the client to develop a complete specification of the scope of the simulation. Ideally, this would be done prior to your response to the Request for
Proposal. Few clients really understand the complexity of the systems they wish to simulate (if they did, they probably would not need the simulation). This specification should include the three most costly parts of every project which include the input interface (customized interfaces are now common), execution and output analysis (what type of reports on which scenarios for how many replications) and process logic (the rules which govern operation of the system and usually the part that requires the greatest amount of simulation coding and testing). Once a specification exists, an experienced consultant can estimate the cost of the project based on similar completed projects. Note to Clients: The specification is a great way to compare simulation consultants. The questions they ask in preparation of the specification will tell you a great deal about their understanding of simulation and the system to be simulated. And remember that every consultant will spend the money allocated - the quality of the result is what you need to compare.

\section{Do a pilot study which includes a basic model and} then estimate the cost for the complete project.

A pilot study is akin to the test well in the oil exploration analogy. In some projects, a specification is impossible until some initial investigation is completed. In all projects, the specification will change after some initial work is completed. Unfortunately, a corporate buyer will usually require a single quotation so simply write a letter of agreement that at week X, a basic model will be presented and an estimate of the cost-to-complete will be justified. Be sure to make some an attempt at developing at least the structural parts of the model; flowcharts and specification documents are much less easier than the actual model development.

\section{Fix the cost based on what you can invest and do the best you can with that limitation.}

While this may not be as scientific as the other approaches, it is a realistic and often used approach. Of course, you only get what you pay for. This is a particularly good approach when there is a lot of uncertainty regarding the project specification or the simulation analyst or client is inexperienced. Unlike the analogy, you can benefit without "striking it rich" as long as you make sure that the simulation process helps build system understanding.

A well-known rule-of-thumb in business is that $90 \%$ of new business failures are due to "inadequate funding". What this means is that the product or service that the business was offering was viable but the financing necessary to establish the firm was insufficient. I suggest the same is true for simulation projects. Inadequate estimation of the cost of simulation projects can 
eliminate a primary cause of project failure - it will always take longe $r$ and cost more than you initially expect. Just keep drilling!

\subsection{Marvin Seppanen: Successful Simulation Projects}

This discussion item is based on 30 years of experience in the field of discrete event simulation, 14 of which as an independent consultant. It is my opinion that the orderly presentation of data is a key element in successful simulation projects. Most simulation tools make it all to easy to imbed critical data into the model logic where it can be lost in terms of model auditing and potentially missed when model changes are required. Since 1984 this author has used personal computer spreadsheets exclusively for all simulation model data input. Spreadsheets have been found to be a concise format through which data can be organized, edited, and most importantly understood by the model user. I use one simple rule in developing simulation models; no internal data is allowed. All numeric data and decision options must be kept external from the simulation model, i.e., in a spreadsheet. Fortunately, this approach has become easier with time and is now so straightforward that it should be universally required.

My first project as an independent consultant involved converting a mainframe SLAM model to SIMAN for operation on a personal computer. The model involved tracking the inventory level of 50 components used to assemble automobiles. Each component name appeared in three separate locations of the SIMAN experimental frame. Maintenance of such a model seemed problematic for users who were more interested in managing the inventory system than learning a complex code structure. As a solution, a Lotus 1-2-3 spreadsheet was used to code the 50 inventory items and their related data. A second spreadsheet was used to supply the general modeling parameters such as shift length and planned daily production. A Basic program was written to read the spreadsheet data in the Data Interchange Format and generate the complete SIMAN experimental frame. Not only was the user saved the difficult task of learning how to edit the SIMAN syntax, but several different assembly plants were modeled by simply constructing new spreadsheets, with no additional modeling coding.

This approach involved writing special purpose code for each application. Fortunately, much of the code could be reused between applications, i.e. reading DIF files and generating Sequence elements. Nonetheless, it has been a time-intensive step in the model development process. However, the payoff permits the user to make a wide range of model modifications by simply changing numbers or options on a set of spreadsheets. In addition, those spreadsheets could be independently printed to serve as model documentation and used to drive other applications. The simple fact that the spreadsheet software can sort and sum data has proved invaluable as a tool to seek out incorrectly entered data.

Over the years the popularity of spreadsheets as a personal computer tool has made their integration into simulation much easier. Spreadsheet improvement such as time/date formats, multi-sheet workbooks, and standardized cut \& paste procedures have all helped. It is also rare today to find a potential simulation user who does not have at least basic spreadsheet skills.

However, the biggest advance in supporting this exchange of data has been Visual Basic for Applications (VBA) supported by all Microsoft Office products and at least one simulation tool, Arena 3.0. All full featured simulation tools will soon support VBA or will rapidly find their market shares diminish among serious simulation model developers. Basically, VBA allows its supporting software to read or write data at will between a wide range of applications. Thus, the simulation model can directly obtain data from an Excel workbook or an Access database and then store the results into another Excel workbook, Word document, or even Powerpoint presentation. It is possible to monitor the results from a currently executing simulation by watching Excel charts being updated as additional data is accumulated.

\subsection{Charles White: Client Needs, Success or Failure}

For a consultant (internal or external) what can really kill a project? What can lead to a rousing success? To answer these questions, we need to step back and address the reason for modeling at all.

For a consultant, an engagement will begin with a decision making situation and client with one or more of the following purposes/goals:

1. improved system understanding,

2. predicting the system behavior under differing conditions,

3. comparison of known alternatives,

4. evaluation of known alternatives,

5. generating new alternatives, and

6. improving system performance.

Further, this client may not have the "final authority" so the modeling project really will have two objectives:

1. helping a client achieve the goal of developing a good solid recommendation, and

2. helping the client justify, support, and sell this recommendation. 
The client will begin by describing the situation in terms of his/her background and experiences; perhaps focusing heavily on recent difficulties or symptoms. The modeling process will move from this situation description to a diagnosis of the situation, a listing of the client's needs/wants (goals), then to a problem definition, and only then to model formulation, development, and execution. There are a wide range of factors that will need to be considered including: the time frame for making the recommendation, the range of possible alternatives, the financial constraints, the political climate, the availability of data, the role the client wants to play in the project, and the availability of people to gather new or better data.

The total modeling process can be usefully divided into four phases:

1. the design phase focusing on helping the sponsor develop a good, complete problem definition,

2. the model formulation phase where the system is described, the modeling tasks are planned, and the roles are assigned [it is important to have review sessions to make sure all agree as to scope, schedule, cost, data sources, and people's roles],

3. the development phase with the tasks of developing, testing, and validating the model, and

4. the implementation phase of running, evaluating, comparing the cases, and then making and selling the recommendations.

\section{Where can things go wrong?}

Two key issues are (1) defining the problem correctly [including data gathering] and then (2) building the model correctly. If one believes in technical expertise [meaning true experts can 'solve' any well defined problem], then the most critical factor is defining the problem correctly. Building the model correctly is a technical task upon which the consultant can get help from his/her peers; but, dealing the correct problem is paramount, as getting the right answer to the wrong problem doesn't help the client.

\section{Where can things go right?}

Two key issues are (1) speed-of-delivery and (2) helping the client to sell the recommendation so effectively that the top management says "we should use simulation on all of our tough problems/decisions". Here experience [on similar problems or problem environments] can help in the early stages and modern tools [with good user interfaces and animation graphics to "show the results"] can help in the latter stages.

\section{SUMMARY}

The success or failure for all simulation users, and consultants in particular, hinges on project execution. Each of the panelists took the challenge of drawing upon his or her experience to highlight success or failure factors so that others might learn. Of course, no one paper can cover all of the factors that influence the success of manufacturing simulation projects. The breadth of applications and project unique issues that arise make this an impossible chore and an interesting job. However, the reader should have noted that each panelist made reference to problem definition as a success factor. If you gain nothing else from this paper, remember to avoid the "ready, shoot, aim" syndrome that sexy software and naive clients encourage.

The intent of this paper is to gain some insights from people who have "been there" and survived. Unfortunately, there is no shortcut for experience so most readers will understand the wisdom contained herein only in retrospect, but at least the messages may help keep people from being overconfident.

\section{AUTHOR BIOGRAPHIES}

F. BRADLEY ARMSTRONG is an Advisory Engineer at the ABB Power T\&D Electric Systems Technology Institute. Prior to joining $\mathrm{ABB}$, he founded the consulting firm Simulation Engineering Associates. He has also worked for Hughes Aircraft Company, Pritsker Corporation, and General Dynamics. He received a B.S. in Mechanical Engineering from the University of Texas at Austin, an M.S. in Industrial Engineering from Purdue University, and a M.S. in Integrated Manufacturing Systems Engineering from North Carolina State University. He is a professionally registered engineer, a senior member of IIE and SME. His current interests include generic modeling, experimental design, and World Class Manufacturing techniques. He was the WSC '95 Exhibits Chair and is the WSC '97 Manufacturing Track Coordinator.

MICHELLE BENJAMIN is currently a Senior Simulation Analyst at the Textile/Clothing Technology Corporation $\left([\mathrm{TC}]^{2}\right)$. She has completed consulting projects that address issues in production assembly systems, warehousing, and transportation. Ms. Benjamin's primary focus in production assembly systems is finite capacity scheduling. She has helped in the development of flexible, data-driven simulation models and animations. She received her B.S. in Industrial Engineering and M.S. in Industrial Engineering and Operations Research from Pennsylvania State University. 
RICH KILGORE is a partner in Thread Technologies, a simulation and scheduling consulting firm which is also the developer of the JAVA-based Silk simulation language and SimMasters industrial simulation workbooks. Dr. Kilgore's experience in simulation began in 1979 in the application of simulation to capacity planning at the Ford Motor Company. He was previously the Vice President of Products for Systems Modeling Corporation. Since 1988, he has been an independent consultant and developer of successful simulation solutions for companies such as McDonnellDouglas Aerospace, Anheuser-Busch, Ralston-Purina, M\&M Mars and Alcoa. Dr. Kilgore holds an MBA from Ohio University and a Ph.D. from the Pennsylvania State University.

MARVIN S. SEPPANEN is the principal Consultant for Productive Systems of Winona, Minnesota, an independent Industrial Engineering consulting firm specializing in simulation modeling and analysis of manufacturing systems. He holds his BME, MSIE, and Ph.D. (Operations Research) degrees from the University of Minnesota. Before starting Productive Systems in 1983, he was an Associate Professor of Industrial Engineering at General Motors Institute and The University of Alabama. His consulting and research activities have been primarily in the area of manufacturing systems simulation. He is a Registered Professional Engineer; Senior Member and chapter officer, Institute of Industrial Engineers; Member, The Society for Computer Simulation; Member, Society of Manufacturing Engineers; and is certified at the Fellow Level by the American Production and Inventory Control Society. He currently teaches simulation to Manufacturing Systems Engineering students at the University of St. Thomas in St. Paul, MN.
CHARLES H. WHITE is a Principal Consultant in Operations Research with the Process Engineering Section of the DuPont Company. He has 30+ years of experience in Consulting and Modeling with a strong focus on Simulation and Mathematical Programming as applied to Business Planning, Plant Design, Research Guidance, Asset Productivity, Continuous Improvement, and Logistics. Dr. White has degrees in Physics, Engineering, and Operations Research from the University of Michigan. During his 30 years with DuPont he also taught courses at the University of Michigan, the University of Delaware, DuPont, General Electric, and for the AIChE. He is a member of IIE, Informs, AIChE, and was the Business Chair for WSC in 1993. 